\title{
Assessing Color Differences of Cotton Fabrics Made from Different Yarns After Abrasion
}

\author{
Sena Cimilli Duru, Hatice Açıkgöz Tufan, Umut Kıvanç Şahin \\ Department of Textile Engineering, Textile Technology and Design Faculty, Istanbul Technical University, Istanbul, Turkey
}

Corresponding Author: Umut Kivanc Sahin, sahinumut3@itu.edu.tr

\begin{abstract}
It is expected from a fabric applied with durable softener agent, not only a smooth, slippery and soft touch but also durable color even after several cycles of use and care. From this point of view, at this study weft knitted fabrics were manufactured using Siro, ring and open-end cotton yarns, bleached and dyed, followed by softening treatment with silicone, cationic and nonionic softeners at 1 and 3\% softener concentration levels. Color strength and lightness values of the treated fabrics were evaluated by considering color changes after abrasion. Since the loss of fibers from a fabric surface during abrasion cycles causes prominent changes in the fabric's color, differentiation in the color that occur after a certain number of abrasion cycles $(2500,5000,7500,10000)$ were also measured for evaluation of the abrasion resistance of a fabric. Considering the yarn type and number of abrasion cycles, interaction effects of those with softener type and softener concentration on color strength and lightness were presented and discussed separately. From the results, it was observed that the color values of fabrics after abrasion cycles are closely related to yarn type, softener type, and concentration. The most significant changes in both $\mathrm{L}^{*}$ and K/S values were obtained after fabric were abraded 2500 cycles. Softener type, as well as concentration, should be decided according to the target color shade before coloration.
\end{abstract}

\author{
ARTICLE HISTORY \\ Received: 10.10 .2019 \\ Accepted: 04.03.2020
}

\section{KEYWORDS}

Siro, ring, open-end, softener, color strength, abrasion resistance, lightness

\section{INTRODUCTION}

Weft knitted fabrics are commonly used in manufacturing textile products including casual wear, bed sheets, baby clothes, and underwear. They provide a high perception of comfort due to the easy recovery of their structure after removing any force previously applied for stretching meaning that the garment easily gets the shape of the moving body [1]. In addition to that, the visual aesthetic properties of knitted fabric are important as well as their functional properties. Color from the aesthetic properties is often considered as the first factor in the selection of a textile product by the consumer [2]. The color of the dyed fabric is expected to withstand the effects of several external agencies including laundering, light, abrasion, etc. as well as to achieve the color desired by the process of dyeing. For assessing the color durability of fabrics, color fastness properties and abrasion behaviors are important [2, 3].

Abrasion resistance is the ability of a textile material to withstand abrasion without losing color and other physical properties. The determination of the abrasion resistance by the change in color is useful to evaluate the degradation of the surface appearance of fabrics during abrasion. While evaluating the results, the decrease in the $\mathrm{K} / \mathrm{S}$ and $\mathrm{C}^{*}$ values and the increase in the $\mathrm{L}^{*}$ values during abrasion is considered an indication that the appearance of the fabrics becomes less saturated and lighter as the abrasion cycles increase which means that the increase of abrasion cycles results in color loss of fabric. The reason for the decrease in $\mathrm{K} / \mathrm{S}$ values and the increase in $\mathrm{L}^{*}$ values is the higher light reflection of smoother surfaces compared to those of rough surfaces [2, 4]. Many studies focused on the investigation

To cite this article: Cimilli Duru S, Açıkgöz Tufan H, Şahin UK. 2020. Assessing color differences of cotton fabrics made from different yarns after abrasion. Tekstil ve Konfeksiyon, 30(2), 108-116. 
of the effects of an increased number of abrasion cycles on color values of knitted and woven fabrics made from different fiber materials such as cotton, wool, polyester, viscose and different yarn structures in different fabric construction parameters [4-11]. Alpay et al [5] showed that fabrics with ring spun and open-end spun weft yarns differ from each other in both reflectance and color difference values, which tend to increase as the abrasion cycles increase. Another study investigated by Alpay et al [4] implied that percentage reflectance values and color difference values of weave patterns that have thicker sirospun weft yarns were more affected by abrasion at all abrasion levels in comparison with the weave patterns that have thinner siro-spun weft yarns. Also, it was found that percentage reflectance values and color difference values of weave patterns that have higher warp and weft densities were more affected by abrasion at all abrasion levels.

In addition to thermal comfort and aesthetic properties, users expect a soft hand feeling from knitted garments. To achieve this, fabric softeners are used in home laundering and textile wet processing as bath additives to further improve fabric hand by lowering the surface friction of a textile structure $[1,5,6]$. The physical arrangement of softener molecules on the fiber surface depends on the ionic nature of the softener molecule and the relative hydrophobicity of the fiber surface. Among the softener types, cationic ones have the best softness and are reasonably durable to laundering. Non-ionic softeners show high lubricity and compatibility and are stable to dry cleaning, extreme $\mathrm{pH}$ conditions, and heat. Silicone softeners provide very high softness, crease recovery, abrasion resistance, and tear strength. Amino-functional silicone softeners containing aminoalkyl groups attached to the poly(dimethyl siloxane) backbone impart improved orientation and substantivity for the fiber, which brings the famous super-soft handle. These softeners are highly costeffective as very small amounts are required to obtain desired properties $[12,13]$. In order to determine the effects of softeners on the abrasion resistance, Ozdil et al [14] applied silicone softeners on socks and found out that the abrasion resistance significantly decreases with the usage of softeners. They concluded that due to the usage of silicone softener the fibers slid over each other and moved away from the surface of the socks providing a smoother surface. Çelik et al [1] investigated the effect of nano-silicone softener application on performance and color properties of knitted fabrics. They found that fabrics with nano-silicone softener exhibited poor abrasion but better pilling resistance and concluded that nano-silicone softener treatment did not have a significant effect on color fastness properties of knitted fabrics. Jatoi et al [15] investigated the effect of silicone softener combinations on physical properties and color yield of colored knitted fabric. The results revealed that the silicon nano-emulsion had better physical properties than micro-, macro- and combinations of nano/micro- and nano/macroemulsion softeners. Parvinzadeh and Najafi [16] treated dyed fabrics with anionic, cationic, nonionic, micro and macro emulsion silicone softeners and investigated color and fastness properties and found that treatment with softeners caused to increase the $\mathrm{C}^{*}$ value of the dyed samples and they became brighter. According to another study of Parvinzadeh [17], nonionic, micro and macro silicone softeners decreased the lightness ( $\mathrm{L}^{*}$ ) of all sulfur-dyed samples while anionic and cationic softeners caused only a slight alteration in lightness.

The objective of the study is to determine the individual effects of softener concentrations for different types of softeners and also to find the optimum softener concentration offering better abrasion resistance performance, softener concentrations were carefully selected depending on actual solid contents of each softener type applied. In previous studies applied softener concentrations were mostly presented over a percentage of the commercial product available. However, it is known that due to ease of application as well as economic reasons commercial softeners are diluted softener solutions and the actual amount of softener in the commercially available softener solution widely varies from one brand to another. Moreover, even when working at different concentration levels of softeners, the effect of concentration appears to be limited mostly due to very low solid content. To do so, fabrics knitted by siro, ring and open-end yarns were used in order to investigate the color strength and lightness values of dyed cotton plain knitted fabrics treated with cationic, non-ionic and silicone softeners at $1 \%$ and $3 \%$ solid content concentration levels. After softener application at different solid content concentration levels, four different cycles of abrasion (2500, 5000, 7500, 10000) were applied to the dyed samples. The color values of the control and abraded fabrics in each experimental group were measured and compared.

\section{EXPERIMENTAL}

In this study, plain knitted fabrics from siro, open-end and ring yarns made of $100 \%$ cotton fibers were used. For this purpose, the laboratory type knitting machine, which helps to save material and energy, was employed. During the production process, all the settings were kept constant in order to investigate the lifetime of the needle at standard conditions. The machine had the same equipment such as automatic oil, take up and feeding system, as an industrial one. Table 1. presents some selected properties of the yarns used in fabric production. EN ISO 2060, ASTM D1422-99 and EN ISO 2062 standard test methods were used for the determination of yarn count, yarn twist, and yarn strength, respectively.

After knitting, fabrics were bleached and dyed in an ATCDYE HT01F lab type exhaust dyeing machine at 1:10 
liquor ratio. $37 \%$ of hydrogen peroxide was used for bleaching of fabrics according to the recipe given in Figure 1. After cold rinsing and neutralization with $0.2 \mathrm{~g} / \mathrm{L}$ Terbinox Ultra AL anti-peroxide agent, the fabrics were reactive dyed at 1:10 liquor ratio using $30 \mathrm{~g} / \mathrm{L}$ salt, $10 \mathrm{~g} / \mathrm{L}$ soda ash with 1\% (owf) Reactive Yellow 145 (C.I.Y.145) dye according to the recipe given in Figure 2. The molecular structure of Reactive Yellow 145 is given in Figure 3. Dyed samples were cooled to $40^{\circ} \mathrm{C}$, hot soaped for 30 minutes at $98{ }^{\circ} \mathrm{C}$ using $2 \mathrm{~g} / \mathrm{L}$ Texapol RSN anionic soap, and hot rinsed for 30 minutes at $98{ }^{\circ} \mathrm{C}$ in distilled water, followed by cold rinsing for 5 minutes in distilled water.

Table 1. Yarn properties

\begin{tabular}{lccc}
\hline & Siro & Ring & Open-End \\
\hline Yarn count (Ne) & 20.12 & 19.88 & 19.72 \\
Yarn twist (turns/m) & 627 & 582 & 618 \\
Yarn strength (cN/tex) & 14.81 & 18.81 & 13.89 \\
Yarn elongation (\%) & 5.83 & 6.67 & 6.25 \\
\hline
\end{tabular}

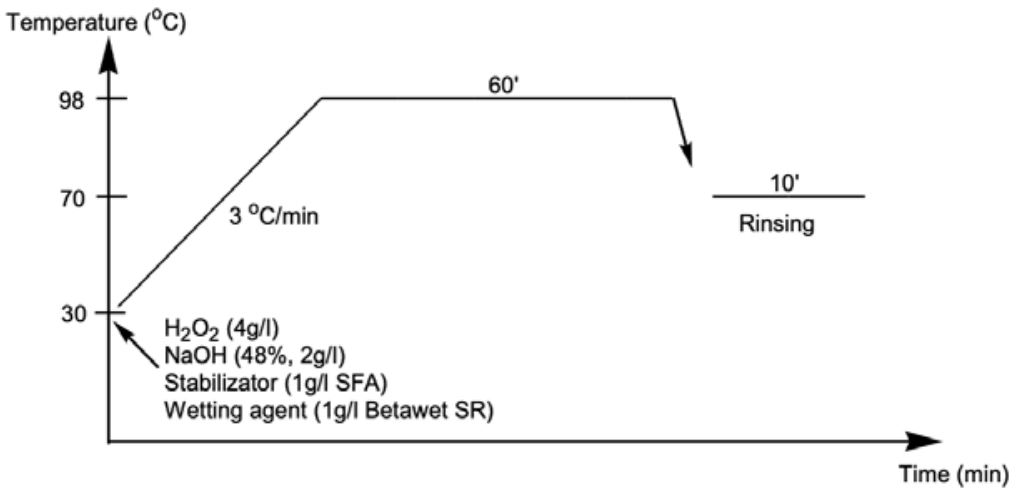

Figure 1. Bleaching recipe

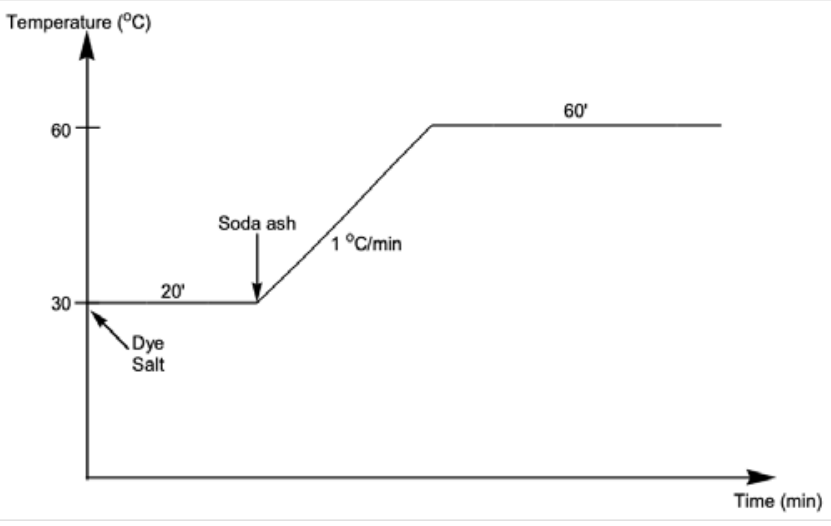

Figure 2. Dyeing recipe

The cationic softener used in this study (SETAFEN SC) was an ethoxylated amine compound with a $\mathrm{pH}$ value of 3.5 to 4.5 in a $10 \%$ solution and solubility in water. The nonionic softener used (SETAFEN PE-N) was a blend of polyethylene emulsions with a $\mathrm{pH}$ value of 7.0 to 8.0 in a $1.5 \mathrm{~g} / \mathrm{L}$ solution and complete solubility in water. The silicone softener used (SETASOFT 1640) was a macroemulsion of amino-functional silicone with a $\mathrm{pH}$ of 5.0 to 5.5 in a $10 \%$ solution and complete solubility in water. To find solid content, 3 grams of each softener were weighed and dried in an oven at $70{ }^{\circ} \mathrm{C}$ for 24 hours and weighed<smiles>NC(=O)Nc1cc(Nc2nc(Cl)nc(Nc3cccc(S(=O)(=O)CCOS(=O)(=O)[O-])c3)n2)ccc1N=Nc1cc2c(S(=O)(=O)[O-])cc(S(=O)(=O)[O-])cc2cc1S([NH3+])(=O)=O</smiles>

Figure 3. Reactive Yellow 145

again. The solid contents of all softeners used were around 20\%. 1 and 3\% softener solutions were prepared considering solid content for each softener type. After setting the $\mathrm{pH}$ of softener solutions with an acetic acid/sodium acetate buffer system, dyed fabrics were padded at $100 \%$ wet-pick-up and dried at $50{ }^{\circ} \mathrm{C}$. Unless mentioned, all solution percentages are expressed as weight on weight. Dyed fabrics without softener applications were tested as control groups. The factors and their levels were chosen for the full-factorial experimental study are given in Table 2. 
Table 2. The factors and their levels were chosen for the experimental study

\begin{tabular}{cc}
\hline Factor & Levels \\
\hline Yarn Type & Siro, Open-end, Ring \\
Softener Applied & Cationic, Non-ionic, Silicone \\
Softener Percentage (\%) & 1,3 \\
\hline
\end{tabular}

Abrasion tests of the fabrics were performed on a Martindale abrasion tester according to the standard of EN ISO 12947-2:2016. Four levels of abrasion cycles (2500, 5000, 7500 and 10000) were applied to the fabrics inserted into the abrasion tester. The color values of the fabrics before and after each level of abrasion cycle were measured according to EN ISO 105 J01:1999 standard. The color values of dyed fabric samples were measured on a Datacolor ${ }^{\circledR} 650$ spectrophotometer using a D65 illuminant and a $10^{\circ}$ standard observer. Each sample was folded twice; four measurements were taken on the sample with a $90^{\circ}$ sample rotation before each measurement. The average of these four measurements was calculated. The K/S and Lightness $\left(\mathrm{L}^{*}\right)$ values were also obtained from the measuring software.
Fabric weight and thickness were tested following the standards EN 12127 and EN ISO 5084 in turn. The following equations were used to calculate the overall porosity:

Porosity (\%) $=\left[1-\frac{\text { Density of fabric }\left(\mathrm{g} / \mathrm{cm}^{3}\right)}{\text { Density of fiber }\left(\mathrm{g} / \mathrm{cm}^{3}\right)}\right] * 100$

Density of fabric $\left(\mathrm{g} / \mathrm{cm}^{3}\right)=\left[\frac{\text { Fabric weight }\left(\mathrm{g} / \mathrm{cm}^{2}\right)}{\text { Fabric thickness }(\mathrm{cm})}\right]$

Properties of fabrics are given in Table 3. The samples were coded such that the first letter shows the yarn type (S-Siro, R-Ring, and O-Open-end), the second letter shows the softener type (C-Cationic, N-Non-ionic, and S-Silicone) and finally, the last one stands for the softener concentration (1, 3 for, $1 \%$, and $3 \%$, respectively).

The statistical evaluation of the data obtained from fullfactorial experiments was performed with the Minitab ${ }^{\circledR} 17$ package program.

Table 3. Properties of the fabrics

\begin{tabular}{ccccc}
\hline Sample code & Thickness (mm) & Weight $\left(\mathbf{g} / \mathbf{m}^{2}\right)$ & $\begin{array}{c}\text { Stitch density } \\
\left(\mathbf{l o o p s} / \mathbf{c m}^{2}\right)\end{array}$ & Porosity (\%) \\
\hline S & 0.592 & 141.59 & 117.25 & 84.26 \\
SC1 & 0.566 & 144.24 & 118.83 & 83.23 \\
SC3 & 0.562 & 140.71 & 126.58 & 83.53 \\
SN1 & 0.538 & 141.59 & 121.00 & 82.69 \\
SN3 & 0.558 & 138.06 & 120.75 & 83.72 \\
SS1 & 0.572 & 138.95 & 122.67 & 84.02 \\
SS3 & 0.558 & 146.88 & 113.75 & 82.68 \\
R & 0.6 & 163.65 & 157.17 & 82.06 \\
RC1 & 0.574 & 163.21 & 159.08 & 81.29 \\
RC3 & 0.558 & 162.32 & 157.33 & 80.86 \\
RN1 & 0.544 & 158.79 & 151.42 & 80.80 \\
RN3 & 0.522 & 158.79 & 149.25 & 79.99 \\
RS1 & 0.568 & 159.24 & 150.75 & 81.56 \\
RS3 & 0.55 & 156.15 & 155.50 & 81.32 \\
O & 0.72 & 196.29 & 177.42 & 82.06 \\
OC1 & 0.66 & 194.08 & 172.50 & 80.65 \\
OC3 & 0.672 & 191.88 & 171.08 & 81.22 \\
ON1 & 0.65 & 192.32 & 169.92 & 80.53 \\
ON3 & 0.644 & 187.91 & 168.08 & 80.80 \\
OS1 & 0.644 & 194.52 & 166.92 & 80.13 \\
OS3 & 0.654 & 186.14 & 172.00 & \\
\hline
\end{tabular}




\section{RESULTS AND DISCUSSION}

\subsection{Effects of yarn structure and softener type on color values of knitted fabrics}

The influence of yarn structure, as well as softener type and concentration levels on lightness values of plain knitted fabrics for each yarn type, were examined. According to the results, the method used for the production of the yarns influenced the lightness of the fabrics that $\mathrm{L}^{*}$ values of the not abraded fabrics made from siro yarns were slightly higher than those of fabrics from ring and open-end yarns in turn (see Figure 4). When the fabric is dyed to a light color like yellow or violet, the light reflection increases with increasing dyestuff concentration, and thus the fabric looks brighter. On the other hand, when a dark color like navy is used in dyeing, the light reflection decreases with increasing dyestuff concentration, and thus the fabric looks darker [12]. Moreover, in siro yarns, the directions of twist in both legs, as well as the final twist direction, are the same which makes the structure smoother when compared with those of ring and open-end yarns causing higher reflectance of light. Thus, the $\mathrm{L}^{*}$ values after coloration were higher for the fabrics made from siro yarns. Due to the wrapper fibers, open-end yarn is more compact than ring yarn which resulted in lower scattering and higher $\mathrm{L}^{*}$ values.

When the effects of yarn type and softener type on lightness values were considered, fabrics made from siro yarn treated with non-ionic softener had higher lightness values. It is seen from Figure 4 that among the chosen variables, the effect of yarn type on $L^{*}$ value was very significant due to the differences of structural properties of yarn types causing different light reflectance characteristics. When the effects of softener type on $\mathrm{L}^{*}$ values considered, it was seen that non-ionic softeners mostly caused higher $\mathrm{L}^{*}$ values than cationic and silicone ones. According to the ANOVA study conducted, there was a statistically significant difference between the $\mathrm{L}^{*}$ values of the fabrics which were treated with different softener types $(\mathrm{F}=4,468$ sig. 0,033). Comprising many O- end groups both cotton fabric and dyestuff tend to attract positively charged cationic or amino-modified silicone softeners due to ionic interactions rather than nonionic softeners adsorption on fabric surface due to weak physical bonding. The higher amount of adsorption on the fabric surface causes scattering of light and thus lowers resulting $L^{*}$ value. On the other hand, the increase in the softener percentage from $1 \%$ to $3 \%$ tended to decrease the lightness values for all softener types as well as yarn types. This could be attributed to softener particles aggregation on the surface of the fiber at high softener concentrations [18].

Figure 5 shows the KS values of the fabrics. The fabrics made from ring yarns had higher KS values than those of open-end and siro ones, respectively, which means that the knitted fabrics from ring yarn performed higher dyeing efficiency than the fabrics from open-end and siro yarns did. When the costs of dyeing were considered, fabrics made from ring yarns might reduce the needs of required dyestuff and auxiliaries to achieve the same shade depth of fabrics from open-end and siro yarns. Also, it was mentioned by Akgun et al [6] that the higher the K/S values, the higher the amount of dyestuff on the fabric and the lower the reflectance of the fabric. In other words, siro yarns did not offer an advantage over the yarns concerning the color values.

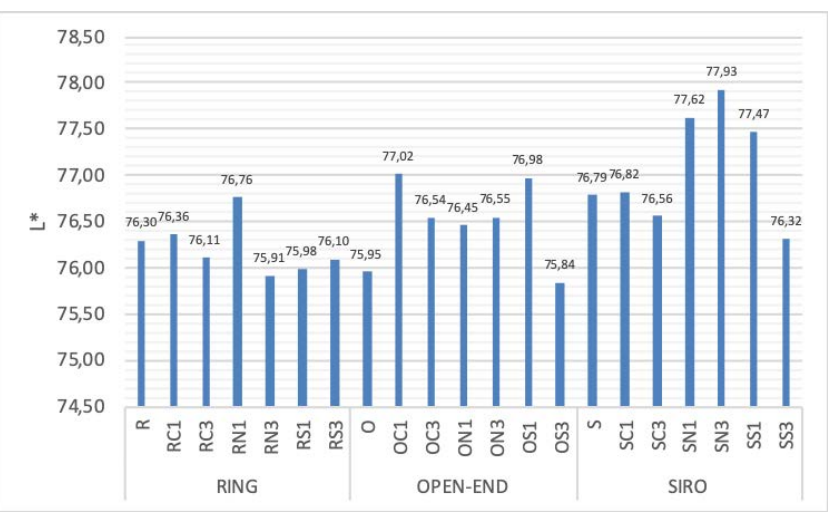

Figure 4. Lightness values of the non-abraded fabrics

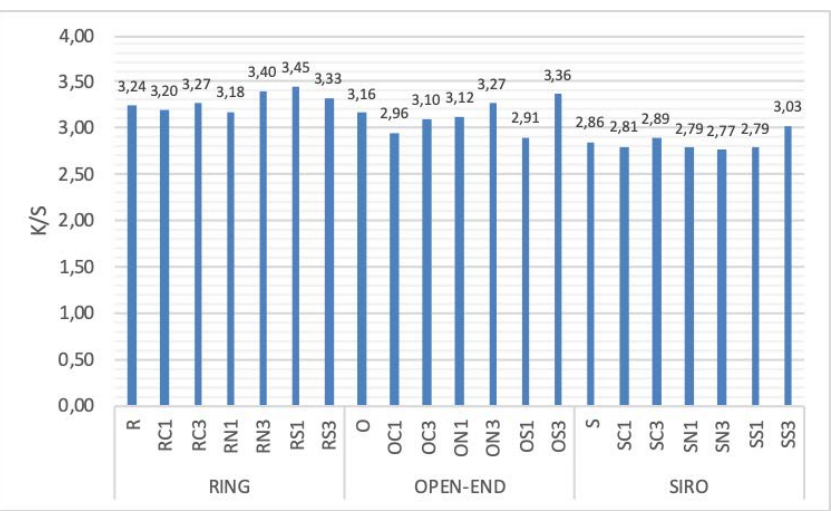

Figure 5. K/S values of the non-abraded fabrics

Irrespective of the softener type and concentration level, fabrics from ring yarns had higher KS values than those of open-end and siro yarns, respectively. It is apparent that different dyeing recipes are needed for cotton fabrics made of different yarn types. When interaction effects of yarn type and softener type on K/S values were considered, fabrics treated with silicone softeners generally showed slightly higher K/S values than those treated with nonionic or cationic ones, probably due to silicone softener having lower refractive index than cotton, and thus, causing lower light reflection [13]. Considering the interaction effects of yarn type and softener concentration, it is seen from Figure 6 that higher softener concentration resulted in higher $\mathrm{K} / \mathrm{S}$, due to a higher amount of chemicals adsorbed on fabric surface causing higher absorption of incoming light. However, for $1 \%$ softener treated fabrics made of open-end yarns, the $\mathrm{K} / \mathrm{S}$ values were lower than those of both untreated and 3\% softener treated fabrics. This was mostly due to a very low $\mathrm{K} / \mathrm{S}$ value of $1 \%$ silicone softener treated fabric made of siro yarn, having a K/S value even lower than that for untreated fabric. It was apparent that a low amount of silicone softener could not spread on the fabric surface evenly, and caused a higher amount of scattering 
due to a less smooth surface structure. As seen from Figure 6 , the interaction effect of softener type and softener concentration on K/S represents that regardless of softener type, increasing softener concentration caused higher K/S, probably due to lower reflection of light. This must be taken into account when calculating the amounts of dyestuff and auxiliary chemicals before dyeing cotton fabric that will encounter softening finish. Preliminary experiments should be conducted to decide the type and concentration of softener to be applied in order to reach demanded softness of the resulting fabric, and then the dyeing recipe should be fine-tuned to match the demanded color shade after finishing.

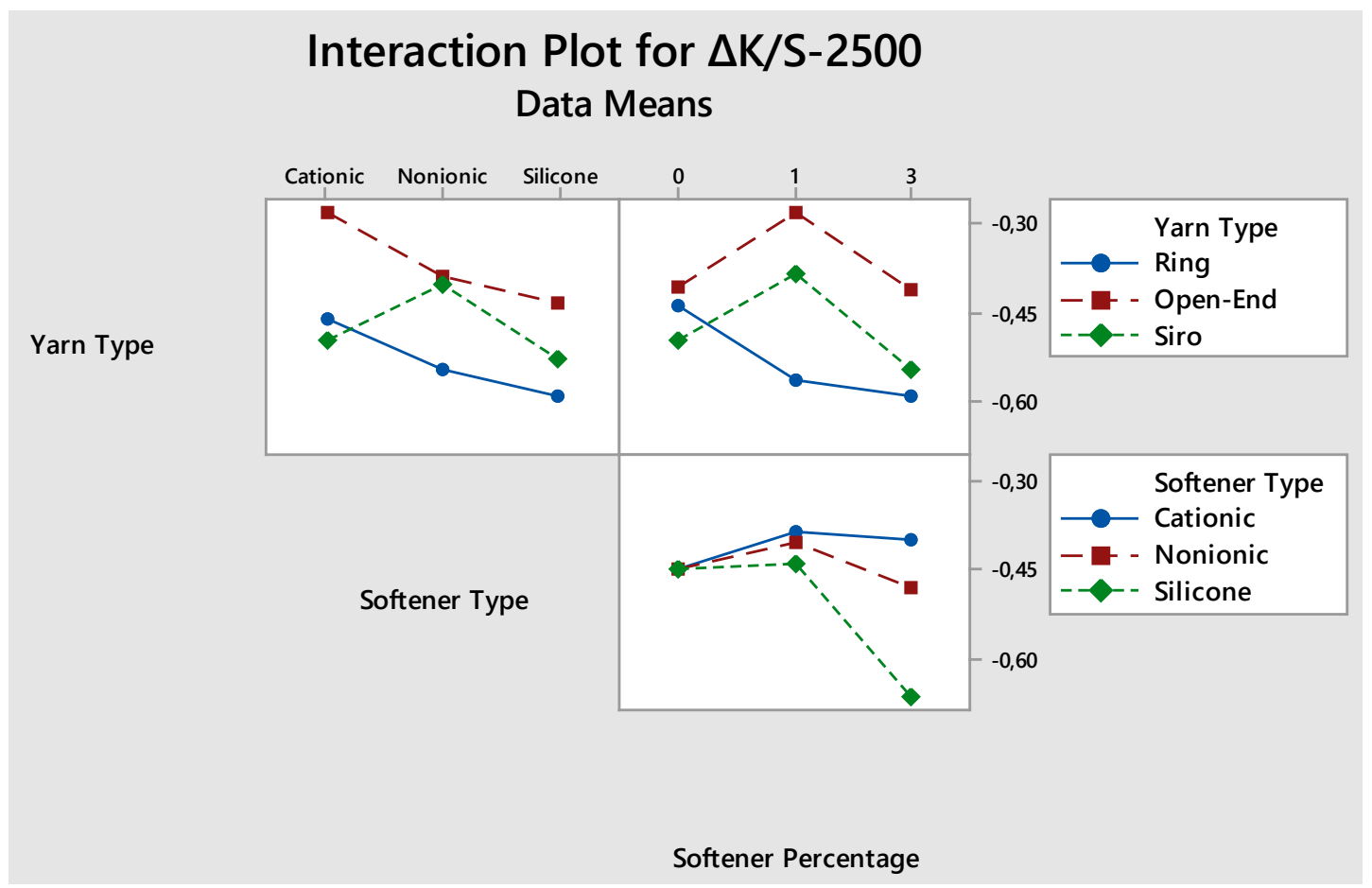

Figure 6. Interaction between yarn type, softener type and concentration on the color strength difference $(\Delta \mathrm{K} / \mathrm{S})$ of fabrics after 2500 abrasion cycles.

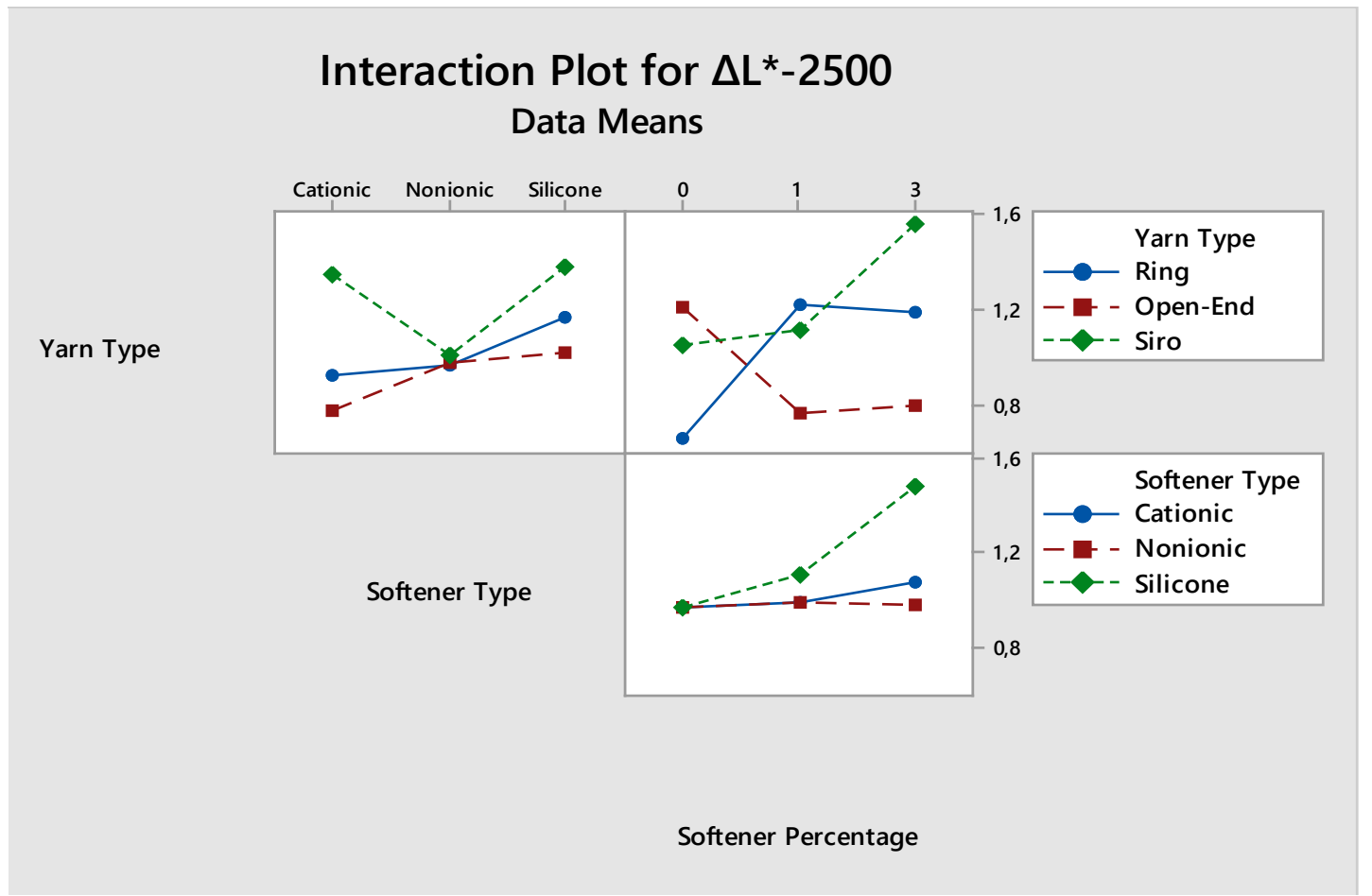

Figure 7. Interaction between yarn type, softener type and concentration on the lightness difference $\left(\Delta \mathrm{L}^{*}\right)$ of fabrics after 2500 abrasion cycles. 


\subsection{Effect of abrasion on color values of knitted fabrics}

In Figure 8 and 9, changes in $L^{*}$ and KS values of cotton plain knitted fabrics with increasing abrasion cycles are presented. The $\mathrm{L}^{*}$ values of all fabrics increased as the abrasion cycles increased while K/S values decreased. The greatest changes in both $\mathrm{L}^{*}$ and $\mathrm{K} / \mathrm{S}$ values were examined between the not abraded fabric and the fabric after 2500 abrasion cycles. There was a small decrease in K/S values while observing a small increase in $\mathrm{L}^{*}$ values after 2500 cycles which was compatible with the literature findings [5], [6], [10]. As previously stated, at earlier stages of abrasion tests, the fabric surface smoothness increases due to the removal of protruding fibers, and that brings higher light reflectance, causing $\mathrm{L}^{*}$ values to increase and K/S values to decrease. At later stages of the test, the change is mostly due to internal abrasion of the fabric, and thus the change in both $\mathrm{L}^{*}$ and $\mathrm{K} / \mathrm{S}$ is limited, especially when reactive dyes which are strongly bonded to fibers are used for dyeing [2], [4], [10].

In order to represent the interaction effects of yarn type, softener type and concentration on change in $\mathrm{L}^{*}$ and $\mathrm{K} / \mathrm{S}$ values after abrasion, the differences between $\mathrm{L}^{*}$ values of non-abraded fabrics and fabrics after 2500 cycles are presented in Figure 7 and that for K/S values presented in Figure 6. When the interaction effect of yarn type and softener type was considered, it was apparent that fabrics performed similarly in terms of change in $\mathrm{L}^{*}$ when they were treated with nonionic softeners. However, fabrics made of siro yarns had a higher difference in light reflectance properties especially those treated with cationic and silicone softeners. As previously stated, fabrics made from siro yarns have lower abrasion resistance [19]; their surface smoothness changes much more than that of ring ones after abrasion testing and thus they offered higher $\Delta \mathrm{L}^{*}$ but lower $\Delta \mathrm{K} / \mathrm{S}$ values. Interaction between softener type and percentage on $\Delta \mathrm{L}^{*}$ and $\Delta \mathrm{K} / \mathrm{S}$ values showed that among the softeners studied, silicone had a higher effect on change in $L^{*}$ and $\Delta \mathrm{K} / \mathrm{S}$ values, the effect is more dominant when the applied concentration was higher. Increasing concentrations of cationic or non-ionic softeners slightly increased $\Delta \mathrm{L}^{*}$ and $\Delta \mathrm{K} / \mathrm{S}$ values. It is postulated that after abrasion testing, long molecular chains of silicone softeners break and cause a fuzzy appearance on the fabric surface, and this is amplified when the concentration is higher. The fuzzy surface causes scattering of incoming light during reflection, and the $\mathrm{L}^{*}$ and K/S values are thus highly affected.
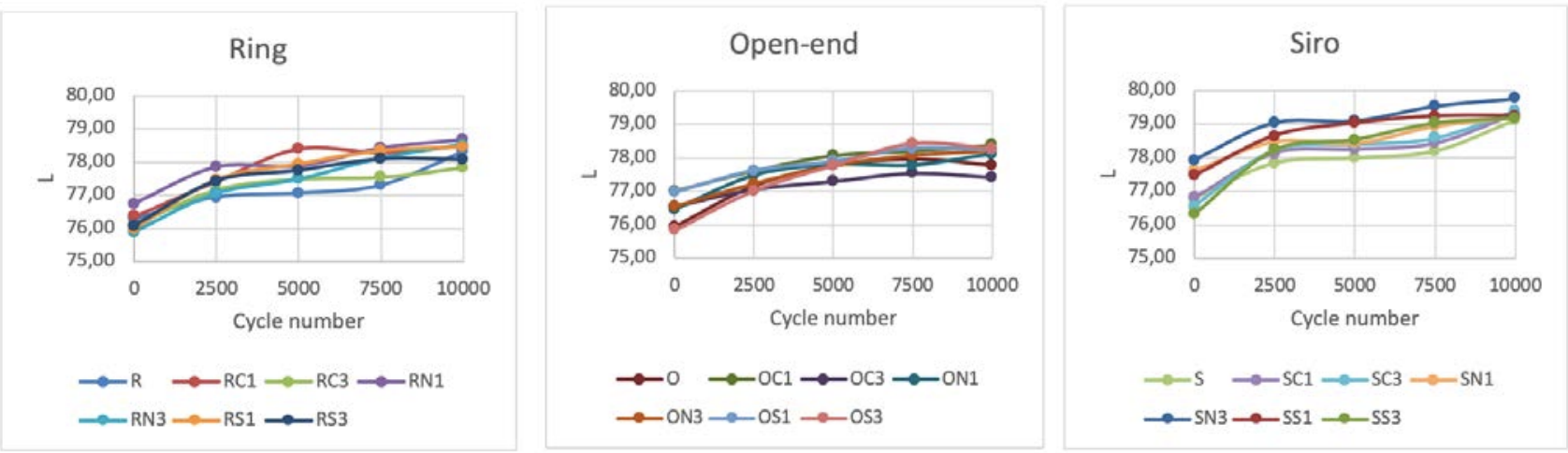

Figure 8. Change in $L^{*}$ values of fabrics with increasing abrasion cycles for the fabrics made with siro, ring, and open-end yarns.
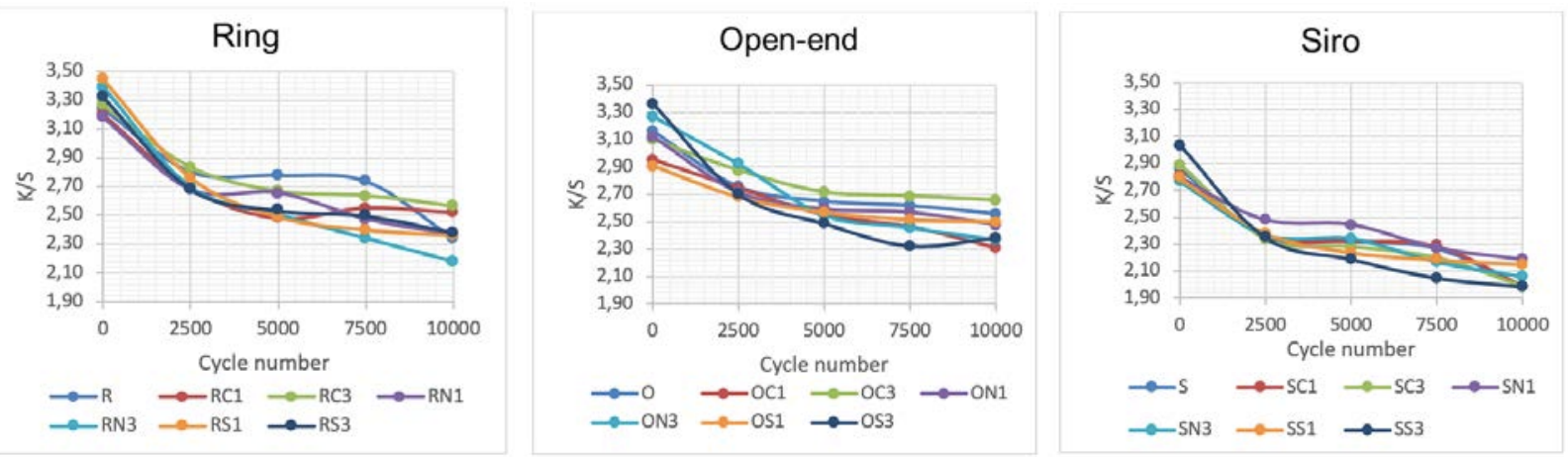

Figure 9. Change in K/S values of fabrics with increasing abrasion cycles for the fabrics made with siro, ring and open-end yarns. 
When the interaction effects of yarn type and softener concentration were considered, it was apparent that fabrics made from open-end yarn had limited $\Delta \mathrm{K} / \mathrm{S}$ values and lower $\Delta \mathrm{L}^{*}$ values when treated with softeners, with a decrease from 1.2 to 0.8 . The softener treatment might have contributed to the abrasion performance of those fabrics by decreasing the friction. On the other hand, fabrics made from ring yarns had higher $\Delta \mathrm{K} / \mathrm{S}$ as well as higher $\Delta \mathrm{L}^{*}$ values after softener treatment with an increase from 0.8 to around 1.2. The softener treatment affects the surface structure, causing higher light reflectance. When fabrics made from siro yarns were considered, it was apparent that an increase in softener concentration over $1 \%$ increased $\Delta \mathrm{L}^{*}$ values, from around 1.2 to 1.6 , and $\Delta \mathrm{K} / \mathrm{S}$ values from around 0.40 to 0.55 . It was apparent that the overuse of softener caused a change in the fabric surface. When individual test results were considered, it was observed that the main reason for the very high difference in $\mathrm{L}^{*}$ and K/S values came from $3 \%$ silicone softener treated fabrics. It was believed that treatment with very high percentages of silicone softeners causes silicone double-layer formation on the fabric surface, changing light reflection properties even more [13].

\section{CONCLUSION}

For this study, Ne 30 (100\%) cotton yarns were knitted into single jersey fabric from three different spinning systems namely siro, ring and open-end yarns. All fabrics were hydrogen peroxide bleached and reactive dyed. In order to investigate the not only effect of softener type but also their concentration levels, the fabrics were treated with cationic, non-ionic or silicone softeners at $1 \%$ or $3 \%$ solid content concentrations. All samples were tested for their abrasion resistance at 2500, 5000, 7500 and 10000 cycles. The $\mathrm{L}^{*}$ and $\mathrm{K} / \mathrm{S}$ values were measured before abrasion test and after each testing cycle to evaluate the effect of yarn structure, together with softener type and concentration on abrasion characteristics of plain jersey fabrics. The results showed that:

1- $L^{*}$ values of non-abraded fabrics change depends on yarn structure. Reflecting more light due to its smoother structure, the fabrics made from siro yarns had higher $\mathrm{L}^{*}$ values and they were followed by ring and open-end in turn.

\section{REFERENCES}

1. Çelik, N., Değirmenci, Z. \& Kaynak, H. K. (2010). Effect of nanosilicone softener on abrasion and pilling resistance and color fastness of knitted fabrics. Tekstil ve Konfeksiyon, 20 (1), 41-47.

2. Gun, A. D. \& Tiber, B. (2011). Color, color fastness and abrasion properties of 50/50 bamboo/cotton blended plain knitted fabrics in three different stitch lengths. Textile Research Journal, 81 (18), 19031915.

3. Gun, A. D., Demircan, B. \& Acikgoz, A. (2014). Colour, abrasion and some colour fastness properties of reactive dyed plain knitted fabrics made from modal viscose fibres. Fibres \& Textiles in Eastern Europe, 22 (5), 107-113. https://doi.org/10.1177/0040517511411967

4. Alpay, H. R., Becerir, B. \& Akgun, M. (2005). Assessment of Reflectance and Color Differences of Wool Fabrics after Abrasion.
2- Due to increased scattering of light when softener adsorption was more, fabrics treated with cationic and silicone softeners had lower $\mathrm{L}^{*}$ values than those with non-ionic softeners. Similarly, an increase in the softener percentage decreased the $\mathrm{L}^{*}$ values of fabrics.

3- The K/S values of fabrics made from ring yarn were higher than those from open-end and siro ones, meaning that the same shade depth on fabric made from ring yarn can be achieved with fewer amounts of dyestuff and auxiliaries when compared to those from open-end and siro yarns.

4- Having a lower refractive index than cotton, silicone softeners caused a decrease in light reflection and fabrics treated with silicone softeners showed slightly higher K/S values than those with non-ionic and cationic ones.

5- When lower softener concentration was applied, softeners could not evenly spread on the fabric surface and less smooth surface structure caused increased scattering and decreased K/S. When softener concentration was higher, the fabric surface got smoother, scattering decreased and K/S increased.

6- The most significant changes in both $\mathrm{L}^{*}$ and K/S values were obtained after fabric were abraded 2500 cycles.

7- Due to their lower abrasion resistance, fabrics made from siro yarns which were especially treated with cationic and silicone softeners had higher $\Delta \mathrm{L} *$ values.

8- Fabrics treated with silicone softeners had higher $\Delta \mathrm{L}^{*}$ and $\Delta \mathrm{K} / \mathrm{S}$ values, especially at higher concentrations.

9- When applying silicone softeners, the percentage of softener must be carefully selected in order to avoid silicone double-layer formation on the fabric surface. Otherwise, light reflection properties of fabric might alter such that the depth of the shade would deviate from the targeted hue.

To sum up, when the area of the end-use of the fabric demands softener finish, yarn type, softener type as well as concentration should be decided according to the target color shade. This will help in avoiding color matching problems and undesired cost issues.

Textile Research Journal, 75 (8), 607-615. https://doi.org/10.1177/ 0040517505057423

5. Alpay, H. R., Becerir, B. \& Akgun, M. (2005). Assessing Reflectance and Color Differences of Cotton Fabrics after Abrasion. Textile $\begin{array}{llll}\text { Research } \quad \text { Journal, } & 75 \text { (4), }\end{array}$ https://doi.org/10.1177/0040517505053807

6. Akgun, M., Becerir, B. \& Alpay, H. R. (2008). Assessment of Color Strength and Chroma Values of Polyester Fabrics having Different Cover Factors after Abrasion. Textile Research Journal, 78 (3), 264271. https://doi.org/0.1177/0040517507085425

7. Akgun, M., Becerir, B., Alpay, H. R., Karaaslan, S. \& Eke, A. (2010). Investigation of the Effect of Yarn Locations on Color Properties of Polyester Automotive Upholstery Woven Fabrics after Abrasion. Textile 
Research Journal, $80 \quad$ (14), $\quad$ 1422-1431. https://doi.org/10.1177/ 0040517510361804

8. Becerir, B., Omeroglu, S. \& Alpay, H. R. (2006). Assessing color differences of cotton fabrics made from ring- and compact-spun yarns after abrasion. AATCC Review, 6 (10), 37-41.

9. Ortlek, H. G., Tutak, M. \& Yolacan, G. (2010). Assessing colour differences of viscose fabrics knitted from vortex-, ring- and open-end rotor-spun yarns after abrasion. Journal of Textile Institute, 101 (4), 310-314. https://doi.org/ 10.1080/00405000802399528

10. Ozturk, M. \& Nergis, B. U. (2008). Determining the dependence of colour values on yarn structure. Coloration Technology, 124 (3), 145150. https://doi.org/10.1111/j.1478-4408.2008.00134.x

11. Akgun, M., Becerir, B. \& Alpay, H. R. (2018). Investigation of the relation between surface roughness and friction properties of polyester fabrics after abrasion. Journal of Textile Institute, 109 (3), 322-337. https://doi.org/10.1080/00405000.2017.1344117

12. Baldwinson, T. M. \& Shore, J. (Ed.) (1990). Colorants and Auxiliaries - Volume I: Colorants. (London).

13. Schindler, W. D. \& Hauser, P. J. (2004). Chemical Finishing of Textiles. Chemical Finishing of Textiles. Elsevier Ltd. https://doi.org/10.1533/9781845690373
14. Özdül, N., Marmarali, A. \& Oğlakcioğlu, N. (2009). The abrasion resistance of socks. International Journal of Clothing Science and Technology, $21 \quad$ (1), 56-63. https://doi.org/10.1108/09556220910923755

15. Jatoi, A. W., Khatri, Z., Ahmed, F. \& Memon, M. H. (2015). Effect of Silicone Nano, Nano/Micro and Nano/Macro-Emulsion softeners on color yield and physical characteristics of dyed cotton fabric. Journal of Surfactants and Detergents, 18 (2), 205-211. https://doi.org/10.1007/s11743-014-1647-5

16. Parvinzadeh, M. \& Najafi, H. (2008). Textile softeners on cotton dyed with direct dyes: reflectance and fastness assessments. Tenside, Surfactants, Detergents, 45 (1), 13-16. https://doi.org/ 10.3139/ 113.100357

17. Parvinzadeh, M. (2007). The effects of softeners on the properties of sulfur-dyed cotton fibers. Journal of Surfactants and Detergents, 10 (4), 219-223. https://doi.org/10.1007/s11743-007-1034-6

18. Parvinzadeh, M., Nemari, N., Shaver, M., Katozian, B., Ahmadi, S. \& Ziadi, I. (2010). Influence of ultrasonic waves on the processing of cotton with cationic softener. Journal of Surfactants and Detergents, 13 (2), 135-141. https://doi.org/10.1007/s11743-009-1158-y

19. Beceren, Y., Candan, C., Cimilli, S. \& Ülger, K. (2010). Properties of plain knits from siro-spun viscose/spandex yarns. Fibres and Textiles in Eastern Europe, 78 (1), 41-46. 